\title{
OJS

\section{TORNAR-SE PROFESSOR DE GEOGRAFIA: UMA ANÁLISE À LUZ DA TEORIA DAS REPRESENTAÇÕES SOCIAIS}

\begin{abstract}
Larissa Sousa Mendes ${ }^{1}$
${ }^{1}$ Doutoranda no Programa de Pós Graduação em Geografia da Universidade Federal do Rio Grande do Norte- UFRN, Mestra em Geografia pela Universidade Federal do Piaú- UFPI (2017- 2019), Graduada em Bacharelado em Direito pelo Centro de Ensino Unificado de Teresina- CEUT (2013) e em Licenciatura em Geografia pela Universidade Estadual do Piauí- UESPI (2016), advogada. E-mail: larissa-mendes10@hotmail.com; http://orcid.org/0000-0001-6673-9164
\end{abstract}

Artigo recebido em 19/05/2020 e aceito em 01/12/2020

\section{RESUMO}

O ser professor de geografia tem sua essência no sentido que se atribui a esse fato materialmente percebido e que nos permite identificá-lo. Este fenômeno tem uma essência que não se reduz apenas ao fato do ser professor enquanto titulação concedida por uma universidade, mas também compreende o sentido real e ideal atribuído, com suas representações que são, ao mesmo tempo, estruturantes e estruturadas por uma realidade percebida. Diante disso, o presente estudo objetivou identificar a representação social do ser professor de geografia partilhada pelos discentes do curso de Licenciatura em Geografia de uma Instituição de Ensino Superior pública localizada em Teresina-PI e comparar as representações dos alunos que estão no início da graduação com aqueles que se encontram na condição de concludentes do mesmo curso. Para tanto, buscou-se apoio na Teoria das Representações Sociais, proposta por Moscovici (1969). Os dados da pesquisa foram produzidos com base no Teste de Associação Livre de Palavras (TALP). A análise dos dados realizou-se conforme a análise de conteúdo categorial com base em Bardin (1986). Como resultados, identificou-se que as representações sobre o ser professor de geografia ocorrem em uma esquematização entre aspectos objetivos, vinculados à baixa remuneração salarial e aspectos subjetivos, relacionados ao sentido do processo de ensino e aprendizagem. Dessa convergência entre o social e o subjetivo os discentes formam a sua consciência, orientando o modo próprio de pensar e agir em relação a profissão docente.

Palavras- chave: Representações sociais; Professor; Geografia.

\section{TO BECOME A GEOGRAPHY TEACHER- AN ANALYSIS IN THE LIGHT OF THE THEORY OF SOCIAL REPRESENTATIONS}

\begin{abstract}
The quintessence of being a geography teacher lies in the sense which is attributed to this materially perceived fact, and which makes an identification possible. This phenomenon's nature is not only reduced to the fact of being a professor as a degree granted by a university; it also comprises the real and ideal attributed meaning with its representations that are structuring and, at the same time, structured by the perceived reality. Given this context, the present study aimed to identify the social representation of being a geography teacher as shared by the students of the Geography Degree course
\end{abstract}


at the a public higher education institution located im Teresina-PI, and to compare the representations of the students who are in the beginning of their graduation with those who are in condition of graduating from the same course. For this purpose, the Theory of Social Representations, as proposed by Moscovici (1969), was used as support, and research data were created based on the Free Word Association Test (TALP). The Analysis of Categorical Content based on Bardin (1986) served to examine that data. It resulted that the representations related to being a geography teacher occur by schematizing between objective aspects, linked to low wages, and subjective ones, related to the meaning of the teaching and learning process. Converging between the social and the subjective, students shape their conscience and direct their own way of thinking and acting with regards to the teaching profession.

Keywords: Social representations; teacher; geography.

\section{DEVENIR PROFESSEUR DE GÉOGRAPHIE: UNE ANALYSE À LA LUMIÈRE DE LA THÉORIE DES REPRÉSENTATIONS SOCIALES}

\section{RÉSUMÉ}

Être professeur de géographie a son essence en ce sens qu'on l'attribue à ce fait matériellement perçu et qui permet de l'identifier. Ce phénomène a une essence qui ne se réduit pas seulement au fait d'être professeur comme titre accordé par une université, mais comprend aussi le sens réel et idéal attribué, avec ses représentations à la fois structurantes et structurées par une réalité perçue. Compte tenu de cela, la présente étude visait à identifier la représentation sociale d'être professeur de géographie partagée par les étudiants du cours de géographie dans un établissement public d' enseignement supérieur situe à Teresina-PI et de comparer les représentations des étudiants qui sont au début de l'obtention du diplôme avec ceux qui sont en état de sortir du même cours. À cette fin, un soutien a été recherché dans la théorie des représentations sociales, proposée par Moscovici (1969). Les données de recherche ont été produites sur la base du Free Word Association Test (TALP). L'analyse des données a été effectuée selon l'analyse du contenu catégoriel basée sur Bardin (1986). En conséquence, il a été identifié que les représentations sur le fait d'être un professeur de géographie se présentent dans un schéma entre des aspects objectifs, liés aux bas salaires et des aspects subjectifs, liés à la signification du processus d'enseignement et d'apprentissage. A partir de cette convergence entre le social et le subjectif, les étudiants forment leur conscience, guidant leur propre façon de penser et d'agir en relation avec le métier d'enseignant.

Mots - clés: Représentations sociales; enseignants; géographie.

\section{INTRODUÇÃO}

Pensar a representação social do professor de geografia para os estudantes do curso de licenciatura em geografia pressupõe, antes de tudo, a análise das representações sociais como um objeto de estudo, definindo o que representa o objeto em seu contexto social, tendo em vista que a representação social do professor é marcada pela história dessa profissão, bem como a própria profissão é, em si, uma construção social e cultural. Assim sendo, a profissão e a sua consequente representação são, ao mesmo tempo, constituídas e constituintes do meio social.

A literatura que discorre quanto à questão do ser professor de geografa no Brasil é concordante em descrever a desvalorização social do magistério. Sousa (2012) descreve que, em termos de política salarial, por exemplo, nas décadas de 1940 e 1950, a remuneração do professor era bastante significativa, uma vez que neste período os professores recebiam mais de dois salários mínimos, 
período em que o salário mínimo atendia às necessidades básicas desse público. Assim, neste aspecto, a profissão docente era atrativa.

O período que se estende de 1950 a 1980 compreende o processo de democratização da educação básica no Brasil, em que houve grande aumento do número de matrículas no ensino público. Apesar desse notório avanço, Sousa (2012) aponta que esse período foi também marcado pela precarização das condições de trabalho do professor, e pelo consequente desprestígio da profissão. Para ele, estariam entre os fatores que contribuíram para esta situação o contexto social assinalado pelo crescimento demográfico e o aumento da demanda por escolarização, exigindo a multiplicação dos postos de trabalho do professor em ritmo superior aos recursos disponíveis para pagamento de vencimentos, resultando, por conseguinte, em baixos salários.

No caso especifico do professor de geografia, essa situação foi agravada pelas reformas de ensino empreendidas no período da ditadura militar brasileira, tais como aquelas relacionadas à substituição gradativa da geografia pelos estudos sociais na grade curricular (Lei $\mathrm{n}^{\circ}$ 5.692/71), ocasionando notadamente uma enorme desvalorização da geografia escolar e do próprio professor desta disciplina, por ter resultado num esforço de negação da identidade de ambos.

$\mathrm{Na}$ década de 1990, sob a forte influência das exigências de organismos internacionais, a exemplo da Organização das Nações Unidas para a Educação, Ciência e Cultura (UNESCO), foram implementadas pelo Estado brasileiro políticas de valorização dos profissionais da educação. Nesse contexto, houve a promulgação da Lei de Diretrizes Bases da Educação - LDB (Lei n 9394/96), a elaboração dos Parâmetros Curriculares e a criação do Fundo de Desenvolvimento do Ensino Fundamental e Valorização do Magistério - FUNDEF (SOUSA, 2012).

Esse período também é marcado pela luta dos professores por melhores condições de trabalho, pela unificação dos planos de carreira, pela aplicação de $10 \%$ do Produto Interno Bruto (PIB) à educação e pela definição do piso salarial nacional para os professores, sendo que esta última conquista apenas concretizou-se em 2008, com a promulgação da Lei $n^{\circ}$ 11.738/08.Todos esses aspectos influenciam na formação de representações sobre o ser professor, podendo influenciar também na forma como os licenciandos e os licenciados constroem seus saberes.

Foi nesse contexto de reorientação política e econômica que houve uma reestruturação da educação superior no Brasil, sobretudo por que a educação superior e sua atribuição de qualificação 
de recursos humanos para a produção econômica e os consequentes lucros gerados interessam ao mercado globalizado e, sobretudo ao sistema econômico capitalista.

Dentro dessa nova lógica, o país adotou políticas econômicas de austeridade, reduzindo o investimento público em áreas estratégicas. Esse processo resultou na elaboração da Emenda Constitucional $n^{\circ}$ 95/2016, que impôs a limitação para os gastos públicos primários. Essa Emenda, conhecida popularmente como Emenda do Teto dos Gastos, delimitou um limite máximo para as despesas primárias do Governo Federal por um período de 20 exercícios financeiros. Essa medida acabou afetando a educação superior pública, uma vez que as Universidades públicas tem boa parte de seu orçamento restrito aos gastos obrigatórios (folha de pagamento e previdência), ficando sem margem para investimentos.

A gravidade dessa situação pôde ser observada quando do corte/contingenciamento do orçamento das universidades públicas pelo MEC em 2019. Momento em que o governo anunciou o congelamento de R $\$ 1,7$ bilhões dos gastos das universidades, de um total de R \$ 49,6 bilhões; bloqueando, assim, uma parte do orçamento das 63 universidades e dos 38 institutos federais de ensino. Estes fatos evidenciam o contexto de movimentos conservadores que tem tentado atacar a autonomia docente e retirar financiamento da educação constituindo-se em retrocessos das políticas públicas atuais que afetam a profissão docente (NASCIMENTO, 2018).

Nesse ínterim, esta pesquisa teve como objeto de investigação as Representações Sociais sobre o ser professor de geografia, partilhadas pelos graduandos do curso de Licenciatura em Geografia de uma Instituição de Ensino Superior pública localizada em Teresina-PI, no ano de 2018.

O interesse pelo estudo desse tema teve início pelo fato de ouvirmos com frequência os posicionamentos dos alunos dos cursos de licenciaturas quanto à desvalorização da profissão docente. A partir disso, questiona-se: Qual a Representação Social dos licenciandos sobre o "ser professor de geografia"? por que ocorre tal fenômeno em cursos cuja habilitação é a licenciatura? Nesse contexto, a pesquisa busca descobrir: $\mathrm{O}$ que está por trás desse comportamento?

A partir desses questionamentos iniciais, e acreditando que as respostas são imprescindíveis para a reflexão sobre a imagem social da profissão docente e seu processo de formação, o presente estudo objetivou, de modo central, identificar a Representação Social do ser professor de geografia partilhada pelos licenciandos do curso de Licenciatura em Geografia e de modo específico, comparar as representações dos alunos que estão no início da graduação com aqueles que se encontram na 
condição de concludentes do mesmo curso, a fim de identificar se há diferenciação nas representações de cada grupo, tendo em vista que os alunos concludentes já tiveram contato com o conhecimento científico sobre o que é ser professor de geografia.

Esta proposta de investigação considera o contexto em que a profissão docente está inserida. Assim, a pesquisa também objetivou, de modo específico, discorrer sobre o processo de construção da imagem social do ser professor de geografia a partir de uma perspectiva histórica do processo de sua formação, buscando compreender a simbologia que representa a condição de ser professor de geografia na sociedade contemporânea.

Atinente às técnicas para o desenvolvimento desta investigação, utilizou-se a aplicação do Teste de Associação Livre de Palavras (TALP), com o objetivo de identificar a representação social dos alunos a respeito do "ser professor de geografia", como também o paradoxo entre a escolha pela profissão de professor e a certeza obtida de imediato, pelo senso comum, no tocante à sua difundida ideia de desvalorização. Desse modo, realizou-se a análise de conteúdo categorial a partir do discurso dos alunos entrevistados.

O conteúdo desta pesquisa será abordado em três partes estruturantes. A primeira parte compreende a construção histórica da imagem social do professor de geografia. Na segunda parte discorreremos sobre os caminhos metodológicos percorridos na investigação e sobre os pressupostos da teoria das representações sociais. Já na terceira parte será exposto o ser professor de geografia a partir do olhar dos alunos no curso de licenciatura.

Feito esse preâmbulo, nesta seção pretende-se refletir sobre o ser professor de geografia a partir do contexto do processo de formação de professores, servindo-se aqui do consequente histórico dessa profissão, posto que as representações sociais são construídas na interação dos indivíduos com o contexto histórico e social do qual eles tomam parte.

\section{A IMAGEM SOCIAL DO SER PROFESSOR DE GEOGRAFIA: ONTEM E HOJE}

O contributo de Profissão Professor é de clarificação. Clarificação do que significa ser professor. O contributo está longe de ser trivial. Ser professor não é algo facilmente definivel. É insatisfatório identificá-lo apenas como aquele que ensina. A sua função é consideravelmente mais complexa do que isso. A complexidade estende-se às diversas áreas da sua actividade e ao seu percurso profissional (NÓVOA, 1991, p. 171). 
O processo de construção da imagem social do ser professor de geografia passa necessariamente por uma discussão abrangente, implicando na necessidade de pensar a docência de um modo mais integrado, considerando-se a dinâmica do ser professor. Assim, é necessário refletir sobre o enfoque histórico e a construção dos saberes docentes que subsidiam a formação do professor.

No que concerne ao histórico da formação inicial do professor de geografia, Rocha (2010, p.1) preleciona que os primeiros cursos são instituídos, no Brasil, a partir do Decreto n 19.851/31, no qual o Ministro Francisco Campos renova o ensino superior brasileiro com a introdução do sistema universitário.

As duas primeiras instituições de ensino superior organizadas sob as novas regras do sistema universitário foram a Universidade de São Paulo, em 1934, e a Universidade do Distrito Federal, em 1938 (ROCHA, 2010). A partir da criação desses cursos de formação inicial de professores de geografia, verifica-se uma mudança tanto cultural quanto institucional, no que concerne ao ser professor dessa disciplina. Isto porque, pela primeira vez, a disciplina de geografia passaria a ser ministrada por um profissional formado especificamente para atuar nessa área.

Assim, em 1950, houve uma maior difusão dos cursos de formação de professores, sobretudo a partir da promulgação da Lei ${ }^{\circ}$ 4024/61, que determinava as Diretrizes e Bases da Educação e regulamentava, em âmbito nacional, a formação docente, especificando a exigência de um currículo mínimo para todos os cursos de Licenciatura em Geografia (ROCHA, 2010).

No bojo das transformações políticas e sociais do período histórico do regime militar, o advento de uma legislação conservadora, materializada pela Lei $n^{\circ} 5.692 / 71$, ocasionou retrocessos para a formação de professores e para a geografia escolar. Nesse contexto,

[...] enquanto na universidade, na década de 70 do século XX, os debates se acirravam em decorrência da busca de novos paradigmas teóricos no âmbito do conhecimento em Geografia, a escola pública de primeiro e segundo graus, hoje ensino fundamental e médio, enfrentava um problema ocasionado pela Lei $\mathrm{n}^{\circ}$ 5.692/71: a criação de Estudos Sociais com a eliminação gradativa da História e da Geografia da grade curricular (PONTUSCHKA; PAGANELLI; CACETE, 2009, p. 59).

Essa política conservadora de precarização da formação do professor de geografia foi reforçada com a criação dos cursos de licenciaturas curtas, em 1972. O projeto que viabilizou a criação dessas licenciaturas preconizava a separação do bacharelado em relação à licenciatura. Isso 
que provocou uma hierarquização e o enfraquecimento da formação científica do professor (SEABRA, 1981).

Embora fossem evidentes os prejuízos que essa nova configuração proporcionaria para a formação do professor de geografia, muitas universidades, sobretudo as privadas, fecharam os cursos de licenciatura em geografia, tendo em vista que seria mais rentável economicamente a implantação das licenciaturas curtas. A transformação da educação em mercadoria materializou-se até mesmo na formação docente.

Pontuschka (2009) afirma que a Associação dos Geógrafos Brasileiros (AGB) e a Associação Nacional de Professores Universitários de História (Anpuh), auxiliaram com críticas, influenciando na extinção dos Estudos Sociais e na configuração de um novo momento, marcado por um novo cenário na formação do professor de geografia, mas que trazia consigo sequelas de todo um processo histórico de precarização da formação docente.

Nesse contexto, para que novos paradigmas da formação docente se concretizem é necessário se conhecer a realidade que se propõe transformar. É necessário então conhecer, do ponto de vista objetivo, a estrutura organizacional na qual o professor está inserido, e, do ponto de vista subjetivo, a dimensão pessoal da formação desse professor. Isso envolve, também, as questões das representações sociais que influenciam a formação desse profissional.

No que concerne a todo o contexto histórico descrito, cabe afirmar que há uma história que não pode ficar no esquecimento, sobretudo porque muito do que houve no passado está presente na atualidade, moldando estereótipos e práticas sobre o ser professor de geografia.

As vicissitudes que permearam a formação e a ação professoral, a exemplo das reformas do sistema escolar brasileiro a partir da década de 1960, sobretudo as implementadas no período da ditadura militar (1964-1985), tais como a substituição gradativa da geografia pelos estudos sociais na grade curricular ( Lei $^{\circ}{ }^{5} 5.692 / 71$ ), bem como o contexto atual de movimentos conservadores que tem tentado atacar a autonomia docente e retirar financiamento da educação ocasionaram uma enorme desvalorização da condição de ser professor.

Houve uma depreciação da profissão docente de modo geral. Mas, o professor de geografia foi um dos que mais perdeu prestígio, sobretudo porque houve uma diminuição na carga horária da disciplina nas escolas, ocasionando o desprestígio da disciplina e da formação do professor, contribuindo para a construção de imagens empobrecidas sobre a geografia escolar e sobre o 
professor dessa disciplina.

Considerando essa realidade, é válido ressaltar a heterogeneidade da profissão docente no Brasil, tendo em vista que cada estado possui condições materiais específicas e de estruturação do campo social geográfico, que influenciam na formação e nas representações sociais do ser professor.

Um dos aspectos dessas diferenças regionais, quanto ao ser professor no Brasil, corresponde à situação salarial. Nesse contexto, cita-se a pesquisa realizada em 2011 pela Associação dos Professores de Estabelecimentos Oficiais do Ceará- OPEOC, que teve como objetivo fazer uma análise comparativa dos salários dos professores da rede estadual nos estados do Brasil.

Esta pesquisa que foi realizada no estado do Piauí, constatou que este estado está em $18^{\circ}$ lugar no ranking da remuneração do professor, entre todos os estados do Brasil. Comprovou ela, ainda, que no ranking regional o Nordeste possui a segunda pior média do Brasil. A partir desses dados, pode-se inferir que as reflexões feitas sobre o ser professor não podem ser dissociadas do contexto em que se configura o campo social no qual a profissão é exercida.

Além do aspecto espacial, a imagem do professor também se diferencia conforme o momento histórico. Gatti e Barreto (2009) afirmam que as primeiras representações sobre a docência denotam a ideia de vocação e missão. Nesse contexto, é importante ressaltar que a educação brasileira nasceu por meio das missões jesuítas e que parte das reminiscências dessa imagem relaciona-se com o período colonial brasileiro (RIBEIRO, 1998). Essas representações contribuíram e contribuem para distanciar os professores da luta por melhores condições de trabalho.

Na perspectiva cientifica, Cavalcanti (2006, p.17) preleciona a concepção de professor, como "profissional do ensino, que tem como principal tarefa cuidar da aprendizagem do aluno, respeitada a sua diversidade pessoal, social e cultural, buscando a formação plena, no âmbito cognitivo, afetivo e social."

No contexto do século XXI configura-se a construção de novos paradigmas educacionais vinculados às mudanças presentes nas práticas culturais pós-modernas e à emergência de novas maneiras pelas quais compreendemos o tempo e o espaço. $\mathrm{O}$ atual momento histórico caracteriza-se pelo surgimento de novas formas de organização social, pelas mudanças na estrutura familiar, pelo aumento significativo das desigualdades sociais, pela transformação na organização do trabalho, pelas transformações tecnológicas, com o surgimento da era da informação, entre outros aspectos que interferem na constituição de uma sociedade cada vez mais complexa (GADOTTI, 2000). 
Ressalta-se que essa conjuntura do campo social e educacional mudou não só o perfil do aluno, mas também o que se espera do professor, surgindo a necessidade de adequação da ação professoral, o que gerou também o sentimento de incerteza quanto à identidade do professor (GADOTTI, 2000).

No âmbito do ensino de geografia há a tentativa de superação do modelo tradicional, marcado pelo ensino dos conteúdos de forma enciclopédica e que se apresentam sem conexões com a realidade do aluno. Outras características desse modelo de ensino correspondem à desconsideração do conhecimento prévio do aluno, o estudo do espaço excluindo o homem como produtor da sociedade e o uso exacerbado da memória pelo aluno, negando-se a possibilidade de compreensão da realidade vivida.

Segundo Gadotti (2000), essa realidade se manifesta devido a alguns fatores, como, por exemplo, a ausência de uma formação de professores coerente com a postura de que a escola das incertezas exige e a inabilidade de lidar com a mudança, sobretudo porque a superação do modelo de professor tradicional representa sair da zona de conforto e assumir a responsabilidade que impede a mudança da escola das verdades para a escola das incertezas. Nessa direção, Morin (2005, p. 16) afirma que "é preciso aprender a navegar em um oceano de incertezas, em meio a arquipélagos de certezas".

Todas essas reformulações na estrutura da sociedade influenciam na construção da representação social do ser professor e, consequentemente, no plano de ação, na escolha da profissão e na constituição de suas práticas. Diante desse contexto, a teoria das Representações Sociais apresenta-se como um caminho para a compreensão dos processos que constituem o ser professor de geografia.

\section{Da complexidade do ser e do saber}

A complexidade da constituição do ser professor de geografia reflete-se nos desafios de ensinar essa disciplina no século XXI. Isto porque todas as transformações históricas e sociais descritas ocasionaram mudanças no sistema educacional, incluindo a não adequação do sistema escolar ao novo contexto social, desencadeando também a necessidade de adaptação da formação do professor a esse novo contexto, e de revalorização da imagem desse profissional na sociedade. Nesse sentido, Esteve (1999, p. 155) afirma, 
[...] quando se discute a situação do magistério brasileiro atualmente é quase que inevitável evocar os índicos de crise que tem afetado a autoridade desse grupo de profissionais. Soma-se a isso as referências às falhas na formação as quais são mencionadas para justificar as deficiências constatadas no aprendizado dos alunos, que tem motivado as críticas à baixa qualidade de nosso sistema de ensino. Também é recorrente a menção ao desprestígio do magistério, que não tem atraído o interesse das novas gerações, causando o decréscimo do número de inscritos no processo de seleção para os cursos de licenciaturas. Cada vez mais surgem dados do que se convencionou chamar de mal-estar docente.

A crise da profissão docente, conforme relatada pelo autor citado, ocorre sob a presença de um mal-estar dos professores, em decorrência das condições de trabalho desfavoráveis, da baixa remuneração salarial, dos casos de violência verbal e física, entre outros fatores que contribuem para o desprestigio da profissão. Dessa forma,

[...] com esse quadro da situação atual do professorado no Brasil se produz uma imagem dos seus membros que pode ser sintetizada da seguinte forma: um profissional mal preparado e com uma remuneração insuficiente, que goza de pouco prestígio na sociedade e cuja legitimidade está sob constante ameaça. Em razão da intensa carga de trabalho adoece facilmente, mas pode faltar às aulas com grande frequência sem prejuízo financeiro para os seus parcos rendimentos. Além disso, tem poucas possibilidades de interferir nas reformas empreendidas no sistema de ensino em que atua e o seu trabalho está cada vez mais sujeito ao controle das instâncias superiores e dos especialistas em educação que de modo geral, desqualificam as suas práticas e as opiniões apresentadas sobre sua própria profissão (VICENTINE; LUGLI; 2009, p. 156).

No caso dessa imagem da profissão docente, as autoras afirmam que se trata do professorado público de modo geral, deixando de lado outros contextos. Isto porque as condições de trabalho são específicas e possuem diferenças significativas quanto à rede pública ou à particular, ou mesmo à etapa da educação na qual os professores lecionam.

A representação social da docência pode ser compreendida sob uma multiplicidade de pontos de vista. Em contrapartida, na imagem normalmente apresentada, há uma visão romântica da educação, comumente difundida em filmes. Nessa imagem, o ser professor resume-se à capacidade de amar, não havendo traços de profissionalismo na atividade desempenhada pelo docente.

Essa representação da profissão distancia-se da realidade, na medida em que desconsidera o ambiente conflitivo em que a docência é realizada. Nesse contexto, a profissão docente é 
compreendida como “dom", “vocação", "missão". Esse discurso atribui ao exercício da profissão um caráter sacerdotal. É justamente essa imagem que constitui uma tentativa de eufemizar as desvantagens de uma profissão, como a baixa rentabilidade econômica (PEREIRA, 1999).

No contexto acadêmico, a formação inicial incentiva à construção da imagem ideal do professor, ou seja, o que o professor deve ser e fazer. Na prática da docência, o professor se depara com todos os desafios e dificuldades inerentes à profissão, e muitas vezes o modelo ideal não corresponde às condições da estrutura educacional e do fazer docente.

Além de toda essa conjuntura, insere-se na questão da complexidade do ser e saber do professor de geografia os desafios que lhe são impostos através da exigência de um conjunto de habilidades, competências e saberes no processo de construção do conhecimento e na sua prática.

Segundo Saviani (2005), o professor, ao realizar sua prática, deve possibilitar aos alunos uma elevação no grau de consciência ao nível filosófico, ultrapassando o alcance do senso comum. Segundo esse estudioso, só é possível a concretização deste processo quando se elimina a concepção fragmentária, desarticulada e mecânica na construção do conhecimento.

Atento a essa realidade, Freire (2011) afirma que ensinar não é transferir conhecimento. É, antes, criar possibilidades para construção e reconstrução do conhecimento e dos próprios modos de conhecer. Nessa perspectiva, a ação professoral exige constante atualização e uma reflexão crítica sobre sua prática e sobre os valores da educação.

Além disso, deve-se considerar que quando o professor ministra suas aulas, ele leva toda sua complexidade existencial consigo. A complexidade do ser e saber reside também na própria condição humana. Nessa direção, Morin (2009) afirma que o ser humano é ao mesmo tempo físico, biológico, psíquico, cultural, social e histórico, sendo que cada disposição exerce influência sobre a outra, constituído a complexidade do ser professor. Complementando, afirma ainda o estudioso em pauta que

[...] devemos compreender que os seres humanos são seres instáveis, nos quais há a possibilidade do melhor e do pior, uns possuindo melhores possibilidades do que outros. Devemos compreender também que os seres possuem múltiplas personalidades potenciais e que tudo depende dos acontecimentos, dos acidentes que ocorrem com eles e que podem liberar alguns deles. (MORIN. 2009, p. 61)

Dessa forma, a ação professoral não é influenciada apenas pelo domínio do conteúdo que o professor detém acerca da disciplina que ministra, pelo caráter profissional ou pela estrutura material 
do ambiente de trabalho, a exemplo da política salarial e das condições da escola. É necessário considerar os aspectos subjetivos que são materializados na sua prática docente.

Nesse sentido, para Pimenta (2010), a prática do professor é influenciada pelas representações sociais construídas ao longo da sua vida. Essas reapresentações sobre o ser professor podem ser formadas a partir da influência da prática de seus próprios professores, das pessoas da família e de outras influências que repercutem na ação de escolha pelo curso de licenciatura e, posteriormente, pela sua permanecia na profissão e na prática em sala de aula.

Assim, concluída esta fundamentação teórica, na seção seguinte, intitulada "Os caminhos metodológicos percorridos na investigação" compreenderemos o percurso metodológico atinente às técnicas de pesquisa, à Teoria das Representações Sociais e aos procedimentos analíticos efetuados.

\section{CAMINHOS METODOLÓGICOS PERCORRIDOS NA INVESTIGAÇÃO E A TEORIA DAS REPRESENTAÇÕES SOCIAIS}

A compreensão da essência da representação social do ser professor de geografia perpassa necessariamente pela pesquisa qualitativa, por meio da qual é possível identificar os significados atribuídos e as representações do objeto de estudo. Desta forma, a pesquisa caracteriza-se como qualitativa com abordagem fenomenológica, pois, incorpora o significado de intencionalidade, uma vez que trabalha com dados subjetivos, representações, valores e opiniões.

A pesquisa foi realizada junto a um grupo composto por 14 graduandos do $2^{\circ}$ período, de um universo de 18, e um outro composto por 12 graduandos do $8^{\circ}$ período, de um universo de 22 . Ambos os grupos faziam parte do curso de Licenciatura em Geografia de uma Instituição de Ensino Superior pública localizada na cidade de Teresina-PI. A quantidade de licenciandos que participaram deste estudo correspondeu a um total de 26 indivíduos, de um universo de 40 compondo a soma total dos dois grupos.

A escolha da referida instituição ocorreu pelo fato da pesquisadora ter sido discente do curso de licenciatura em geografia e, a partir de suas vivências no cotidiano acadêmico desse curso, surgiu a motivação para situar a problemática relacionada aos diversos posicionamentos dos alunos do curso de licenciatura quanto ao ser professor dessa disciplina. Como representação inicial a ser considerada, partiu-se aqui da manifestação cotidiana, no curso, de discursos que, de forma recorrente, revelavam a desvalorização da profissão docente. 
Atinente às técnicas, utilizou-se o Teste de Associação Livre de Palavras (TALP), que constitui um instrumento privilegiado para a captura das representações sociais dos alunos. Segundo Spink (1995, p. 101), “[...] esta técnica por se prestar à análise multivariável, permite superar o que seria um dos problemas mais sérios da análise de conteúdo, ou seja, o caráter puramente hermenêutico das interpretações".

A aplicação do TALP possuiu o objetivo de identificar a representação social do ser professor de Geografia. A associação livre de palavras consiste no pronunciamento, pelos participantes, de palavras que lhes venham à mente a partir de um estímulo que lhes foi dado. No TALP aplicado aos discentes participantes foi utilizada a expressão de estímulo: "ser professor de geografia".

Diante do estímulo indutor, os alunos, individualmente, transcreveram um total de três palavras. Em seguida, os discentes foram orientados a hierarquizar, numa ordem de importância, as palavras evocadas e atribuir significado à palavra apontada como a mais importante dentre àquelas evocadas.

Após a aplicação do TALP, as palavras evocadas, os conceitos atribuídos às palavras descriminadas como mais importantes, tiveram tratamento com a análise de conteúdo, que por sua vez auxiliou na identificação e na compreensão da conotação dada pelos participantes aos elementos que constituem a representação social do professor de geografia.

Ressalta-se que foi aplicado o Teste de Associação Livre de Palavras- TALP aos discentes que estavam presentes no momento em que os procuramos em suas devidas salas de aula. Todos os sujeitos foram informados dos procedimentos e dos objetivos da pesquisa no Termo de Livre Consentimento, bem como foi facultada aos discentes a escolha em participar da pesquisa.

Ao procurarmos sistematizar o discurso dos discentes, em relação ao significado do ser professor de geografia, buscou-se entender a essência desses discursos a partir das considerações de Bardin (1977), que concebe a análise de conteúdo como um instrumento para qualificar as vivências do sujeito, bem como suas percepções sobre determinado objeto e seus fenômenos.

Nesse ínterim, destaca-se a teoria central que norteou a fundamentação da pesquisa, a Teoria das Representações Sociais. Nessa perspectiva, trabalhar a representação social apropriando-se da mesma como teoria ou como fenômeno constitui tarefa complexa, pois nos permite a apreensão da ordem simbólica do "ser professor", rompendo com a dicotomia estabelecida entre o exterior e o interior, naquilo que qualifica a essência da manifestação de um fenômeno. 
A Teoria das Representações Sociais foi sistematizada por Serge Moscovici a partir das formulações de Durkheim, quanto às formas de pensamento social. Moscovici (1978) reconhece a importância da contribuição de Durkheim quanto ao estudo das representações como imagem e discurso, bem como parte integrante da reprodução e transformação de toda ordem simbólica. No entanto, o sociólogo francês distinguiu-se significativamente de seu antecessor, pois reconhece o papel de agente do indivíduo no processo de criação de uma representação, não admitindo uma sobreposição do social ao individual, na medida em que seu conceito de sociedade é dialético.

Ressalta-se que a importância que as representações sociais têm está na função que elas possuem. Elas são fundamentais para a organização e a orientação do comportamento e do modo como se comunicam os indivíduos na vivência em sociedade, sobretudo ao transitarem pelos distintos campos inerentes às organizações sociais humanas. Moscovici destaca que as representações sociais representam aquilo que,

[...] no final das contas produz e determina os comportamentos, pois define simultaneamente a natureza dos estímulos que nos cercam e nos provocam e o significado das respostas a dar-lhes. Em poucas palavras, a representação social é uma modalidade de conhecimento particular que tem por função a elaboração de comportamentos e a comunicação entre indivíduos. (1978, p. 26)

Considera-se, portanto, que as representações sociais possuem como função precípua a orientação de condutas, além de interferir no processo de difusão do conhecimento e na construção de uma identidade social.

Salienta-se que embora se tenha discutido o ser professor de geografia na perspectiva dos alunos em processo de formação docente, importa reconhecer que a formação das representações sociais ocorre contextualizada com o campo social geográfico, e que elas estão sujeitas a interferências externas.

Nessa perspectiva, pode-se afirmar que a escolha pelo currículo do curso de licenciatura, a escolha pela profissão docente, a construção da identidade do ser professor e sua prática em sala de aula e a própria representação social do ser professor de geografia, não são fenômenos que se manifestam por acaso, tendo em vista que há, nessa constituição de eventos, relações indissociáveis entre identidade e subjetividade.

Isso acontece, sobretudo, porque a formação do ser professor e sua prática acontecem em um sistema dinâmico, complexo e processual, que é construído em um contexto de intercomunicabilidade 
de representações, que vai além da racionalidade instrumental e que envolve uma práxis reflexiva, mudanças e incertezas.

\section{SER PROFESSOR DE GEOGRAFIA: O OLHAR DO ALUNO NO CURSO DE LICENCIATURA}

O presente processo investigativo busca analisar o ser professor a partir do olhar de alguns futuros professores que se encontram em processo de formação docente. Acredita-se que identificar a representação do ser professor pode permitir apreender a profissão docente na relação que envolve elementos do campo pessoal e do profissional.

Nesse sentido, Nóvoa (1997) afirma a urgência da interação entre a dimensão pessoal e a profissional, a fim de permitir ao professor a apropriação do seu processo de formação. Entende-se que essa interação só poderá ser concretizada quando o pensamento do professor e do licenciando for conhecido, podendo, a partir do estudo de suas representações, viabilizar contribuições ao processo de diagnóstico das necessidades formativas docentes. Além de fornecer indícios de como os discentes agem no seu processo formativo, tendo em vista que as representações sociais têm a finalidade de orientar as atitudes em sociedade.

A partir dessa compreensão, apresentam-se, a seguir, as palavras evocadas pelos discentes do $2^{\circ}$ período, produzidas como dados primários de pesquisa a partir da expressão estímulo "ser professor de geografia":

Aluno B II (2) ${ }^{i}$ :Missão, conhecimento e magistério. Aluno B II (2):Pesquisador, mentor e espelho. Aluno B II (3): Força, dom e dedicação. Aluno B II (4): Conhecimento, importante e aprendizado. Aluno B II (5): Mediador, conhecimento e consideração. Aluno B II (6): Pesquisador, humanista e crítico. Aluno B II (7): Profissional, mestre e conhecedor. Aluno B II (8):Instrumento, educador e conhecimento. Aluno B II (9): Intelectual, analista e pensador. Aluno B II (10): Ensinar, disciplinar e compromisso. Aluno B II (11):Dinâmico, profissional e pesquisador. Aluno $B$ II (12): Ensinar, aprender e compreender. Aluno $B$ II (13): Amigo, instrutor e mestre. Aluno B II (14): Conhecimento, educar e Inspirar.

O quadro 1, contém as palavras escolhidas pelos discentes como mais importantes, assim como também as conceituações atribuídas sobre a representação do ser professor de geografia. 
Quadro 1- Principais palavras evocadas com o significado atribuído ao ser professor de geografia pelos discentes do $2^{\circ}$ período.

\begin{tabular}{|c|c|c|}
\hline \multirow{14}{*}{$\begin{array}{c}\text { SIGNIFICADO } \\
\text { DAS PALAVRAS } \\
\text { MAIS } \\
\text { IMPORTANTES }\end{array}$} & \multicolumn{2}{|c|}{ Frase Evocativa: Representação sobre SER PROFESSOR DE GEOGRAFIA } \\
\hline & Resposta TALP (1) & $\begin{array}{l}\text { CONHECIMENTO: todo bom professor de geografia é um } \\
\text { cientista, conhecedor do homem e da Terra. }\end{array}$ \\
\hline & Resposta TALP (2) & MENTOR: exemplo a ser seguido. \\
\hline & Resposta TALP (3) & $\begin{array}{l}\text { DEDICAÇÃO: o professor de geografia precisa se dedicar } \\
\text { bastante para exercer sua profissão. }\end{array}$ \\
\hline & Resposta TALP (4) & CONHECIMENTO: é o mínimo para ser um bom professor. \\
\hline & Resposta TALP (5) & MEDIADOR: não ser o dono da verdade. \\
\hline & Resposta TALP (6) & $\begin{array}{l}\text { PESQUISADOR: atuar em todas as áreas da geografia, } \\
\text { utilizando a interdisciplinaridade, para analisar a geografia } \\
\text { como espaço e ciência. }\end{array}$ \\
\hline & Resposta TALP (7) & PROFISSIONAL: habilidade para executar sua profissão. \\
\hline & Resposta TALP (8) & $\begin{array}{l}\text { EDUCADOR: o responsável por medir as mentes das } \\
\text { pessoas. }\end{array}$ \\
\hline & Resposta TALP (9) & INTELECTUAL: alguém com apurado poder de raciocínio. \\
\hline & Resposta TALP (10) & ENSINAR: processo de difusão do conhecimento. \\
\hline & Resposta TALP (11) & PROFISSIONAL: desempenha uma função na sociedade. \\
\hline & Resposta TALP (12) & ENSINAR: levar conhecimento a todos. \\
\hline & Resposta TALP (13) & INSPIRAR: dar motivação para fazer as escolhas da vida. \\
\hline
\end{tabular}

Fonte: Organização da autora, 2018.

A primeira constatação é de que, dentre as palavras ventiladas pelos discentes do $2^{\circ}$ período, quanto à representação do ser professor de geografia, houve apenas duas repetições, que se referem aos termos ensinar, conhecimento e profissional, sendo que cada termo foi repetido duas vezes por discentes distintos.

As palavras ensinar e educador foram definidas pelos Alunos B II (7), (10) e (12) respectivamente, como "processo de difusão do conhecimento" e "levar conhecimento a todos" e "o responsável por medir as mentes das pessoas”. Nestas acepções, o ser professor de geografia é vinculado a uma característica centralizadora, ao tempo em que há a personificação da "imagem" do professor como aquele que detém o conhecimento, aquele que ensina.

Essas representações não vão ao encontro daquilo que é propugnado pelas teorias produzidas no campo das ciências da educação, em especial aquelas que se vinculam ao ensino de Geografia. Acredita-se que pode estar na formação inicial uma das possibilidades de mudança da essência dessas 
representações sociais, assim como também a promoção de uma identidade docente a ser construída de forma processual no campo social acadêmico.

Diante das exigências da educação na atualidade, o exercício da função do professor tem se tornado cada vez mais complexo. Assim, sua função não se restringe a apenas ensinar e transmitir conhecimentos.

Segundo Pereira (2000), o fato do licenciando representar o "ser professor" como um transmissor de conhecimento, ou apenas como aquele que ensina, pode ter ligação, ou ser reforçado, com os currículos dos cursos de licenciatura, baseados apenas no que ensinar, reforçando a ideia do professor como centro do processo de ensino e aprendizagem. Assim,

As representações influenciam a construção da realidade, por exemplo, no momento de pensar o currículo das licenciaturas, ao mesmo tempo que a realidade influencia a constituição dessas representações, a própria estrutura do currículo construído e reconstruído, determina ideias e concepções sobre o ensino (PEREIRA, 2000, p.134).

Nesse ínterim, os Alunos B II (2) e (13), em sentido divergente das representações aqui já expostas, representaram o professor de geografia através dos termos mentor e inspirar, conceituandoos como "exemplo a ser seguido" e "dar motivação para fazer as escolhas da vida". Essas evocações trazem em seu conteúdo a questão da função do professor, que vai além do caráter cognitivo presente nas representações. Nessa acepção, o ser professor está vinculado a uma dimensão afetiva.

Considera-se importante destacar como a representação do ser professor se manifesta nas evocações dos discentes a partir da discussão sobre as teorias científicas implícitas nas suas falas. Nessa direção, são oportunas as considerações de Moscovici (1978), que explica que a localização das representações sociais na interface dos conceitos sociológicos e psicológicos faz implicar seus processos de dinâmicas sociais e psíquicas na elaboração de um sistema teórico complexo.

Corroborando com esse entendimento, Jodelet (2001, p.26) afirma:

As representações sociais devem ser estudadas articulando os elementos afetivos, mentais e sociais e integrando-a o lado da cognição, da linguagem e da comunicação - a consideração das relações sociais que afetam as representações e a realidade material, social e ideativa sobre a qual elas têm que intervir. 
Assim, chama-se a atenção para a dimensão afetiva e subjetiva, do ser professor, nas evocações "mentor" e "inspirar". Nesse sentido, Kaercher (2011, p. 2) afirma que, "[...] bom ou mau, o professor é sempre modelar". Dessa forma, pode-se inferir que essa "imagem" do ser professor está vinculada à transmissão de valores e princípios, influenciando no processo de ensino e aprendizagem e na construção da subjetividade dos alunos para além do ensino de conteúdo.

Já para os Alunos B II (3), (7), (9), ser professor de Geografia é "habilidade para executar sua profissão", "desempenha uma função na sociedade" e "precisa se dedicar bastante para exercer sua profissão". Nesses discursos percebe-se a dimensão da função social e da profissionalização docente.

Nas evocações pesquisador e conhecimento, este último com duas repetições por discentes distintos, o ser professor é representado como cientista e sujeito epistêmico, o que fica evidente nas significações atribuídas por eles: "atuar em todas as áreas da geografia, utilizando a interdisciplinaridade, para analisar a geografia como espaço e ciência", "todo bom professor de geografia é um cientista, conhecedor do homem e da Terra" e "é o mínimo para ser um bom professor”. Nessa direção, Tardif (2002, p. 191) afirma:

[...] o primeiro desses excessos (o professor como sujeito epistêmico) reside na ideia de que o professor se define essencialmente como um ator dotado de uma racionalidade baseada exclusivamente na cognição, ou seja, no conhecimento. Nas ciências da educação, várias concepções atuais do saber docente, da atividade docente e da formação de professores se apoiam num modelo do professor ao qual elas atribuem uma racionalidade definida como um repertório de competências e de desempenhos pensados quase que exclusivamente em termos de saberes, de conhecimentos.

Nessa concepção, o professor é definido como sujeito científico, ou essencialmente pelo caráter que o apresenta como mediador do saber. Chama-se também a atenção para a expressão generalizante da função do professor como "conhecedor do homem e da Terra". Esse discernimento revela a imagem do professor promotor de uma ciência de síntese.

Os Alunos B II (5) e (9) representaram o ser professor de geografia por meio dos termos mediador e intelectual, definindo-os, nesta ordem, como "não ser o dono da verdade" e "alguém com apurado poder de raciocínio". De acordo com esta última concepção, verifica-se uma suposta "valorização" da profissão docente, no sentido da sua não redução ao status de técnicos que apenas cumprem os objetivos definidos pelos especialistas. 
Em síntese, observa-se que os discentes do $2^{\circ}$ período representam e atribuem sentido ao "ser professor de geografia" de forma diversificada, e cada faceta revelada não exclui as demais. Pode-se afirmar que o fenômeno não se mostra sempre pela mesma face ou do mesmo modo. O ser professor de geografia tem sua essência no sentido que se atribui a esse fato materialmente percebido e por meio daquilo que nos permite identificá-lo.

O fenômeno representacional do ser professor de geografia implica na construção de sistemas de identificação social que conferem materialidade ao sentido de ser professor. Esse processo não é meramente cognitivo e de classificação dos significados e sentidos atribuídos a determinado objeto. Há nesse processo uma dimensão atitudinal, que corresponde à função das representações de servir de guia, na orientação de condutas no campo social em que os sujeitos circulam.

Dessa forma, pode-se afirmar que as relações dos discentes com as disciplinas do curso de licenciatura, e com a escolha do curso, ocorrem também mediadas por uma dimensão simbólica, que não é construída em um vazio social, e sim na abrangência, a um só tempo, simbólica e empírica do campo geográfico.

A inserção dos discentes neste campo decorre da acumulação de um conjunto de capitais, entre eles o capital cultural e simbólico, que foram construídos na trajetória social desses sujeitos e que também é influenciado por sua inserção em outros campos, a exemplo do campo escolar.

Assim, pode-se inferir que a identidade e habitus professoral não são construídos apenas no exercício da profissão. As práticas docentes às quais os sujeitos foram submetidos no campo escolar, desde a educação básica, corroboram para a formação de representações sobre os conceitos e os conteúdos ministrados, bem como possibilita a incorporação de modos do ser professor. Há em todo esse processo a incorporação de esquemas mentais, que Bourdieu (1979) denomina de hexis corporal e que se manifestam nas falas e nos gestos dos sujeitos, em suas ações e nas suas representações relacionadas à profissão docente.

Nesse sentido, para a identificação e análise da representação social do ser professor de geografia, registraram-se as palavras que foram evocadas pelos discentes do $8^{\circ}$ período e que estão dispostas, a seguir, na ordem em que foram evocadas no cognitivo desses estudantes e, posteriormente, transcritas para o TALP:

Aluno B VIII (1) ${ }^{i i}$ : Profissional, conhecimento, intelectual. Aluno B VIII (2): vocação, realização e compromisso. Aluno B VIII (3): mediador, instrutor e orientador. 
Aluno B VIII (4): transformador, ensino e ativista.

Aluno $B$ VIII (5): desenvolvimento, ensino e aprendizagem.

Aluno B VIII (6): crítico, educador e intelectual.

Aluno B VIII (7): aprendizagem, transformador, ensino.

Aluno B VIII (8): profissão, ensinar, vocação.

Aluno B VIII (9): orientador, influenciar, exemplo.

Aluno B VIII (10): criticar, ensinar e espaço.

Aluno B VIII (11): missão, ensinar, cidadania.

Aluno B VIII (12): educação, vocação, aprendizagem.

O quadro 2, a seguir, contém as palavras elegidas pelos discentes do $8^{\circ}$ período como as principais, e os significados delas, conforme explicação dada pelos sujeitos, quanto à representação sobre o ser professor.

Quadro 2- Principais palavras evocadas com o significado atribuído ao ser professor de geografia pelos discentes do $8^{\circ}$ período.

\begin{tabular}{|c|c|c|}
\hline \multirow{12}{*}{$\begin{array}{l}\text { SIGNIFICADO } \\
\text { DAS PALAVRAS } \\
\text { MAIS } \\
\text { IMPORTANTES }\end{array}$} & \multicolumn{2}{|c|}{ Frase Evocativa: Representação sobre SER PROFESSOR DE GEOGRAFIA } \\
\hline & Resposta TALP (1) & $\begin{array}{l}\text { PROFISSIONAL: incentiva o aluno a memorizar os } \\
\text { conhecimentos da geografia e a analisar o espaço. }\end{array}$ \\
\hline & Resposta TALP (2) & REALIZAÇÃO: gostar de ser professor. \\
\hline & Resposta TALP (3) & $\begin{array}{l}\text { MEDIADOR: auxiliar o desenvolvimento do aluno por meio } \\
\text { da aprendizagem. }\end{array}$ \\
\hline & Resposta TALP (4) & $\begin{array}{l}\text { ATIVISTA: agente transformador da sociedade através da } \\
\text { educação. }\end{array}$ \\
\hline & Resposta TALP (5) & $\begin{array}{l}\text { DESENVOLVIMENTO: é ajudar no desenvolvimento do } \\
\text { aluno para que ele possa aprender analisar a sua realidade com } \\
\text { um olhar crítico. }\end{array}$ \\
\hline & Resposta TALP (6) & CRÍTICO: ver a sociedade com um olhar crítico. \\
\hline & Resposta TALP (7) & APRENDIZAGEM: intervir para que o aluno possa aprender. \\
\hline & Resposta TALP (8) & $\begin{array}{l}\text { VOCAÇÃO: é preciso ter vocação para ser professor e superar } \\
\text { as dificuldades. }\end{array}$ \\
\hline & Resposta TALP (9) & $\begin{array}{l}\text { ORIENTADOR: orientar pra aprendizagem do aluno com o } \\
\text { desenvolvimento do senso crítico. }\end{array}$ \\
\hline & Resposta TALP (10) & $\begin{array}{l}\text { ENSINAR: buscar instrumentos para efetivar aprendizagem da } \\
\text { analise espacial. }\end{array}$ \\
\hline & Resposta TALP (11) & MISSÃO: ter o dom de ensinar. \\
\hline
\end{tabular}




\section{Resposta TALP (12) $\quad$ APRENDIZAGEM: ajudar o aluno a aprender.}

Fonte: Organização da autora, 2018.

De modo genérico, os discentes do $8^{\circ}$ período mostram uma representação do ser professor ancorada nos pressupostos científicos da didática crítico-social, por meio da qual o ensino é visto como um processo de conhecimento construído aluno e mediado pelo professor. Nesse entendimento, o ensino implica em uma intervenção intencional própria do ato docente que,

[...] diz respeito à articulação de determinados objetivos, conteúdos e métodos que levem em conta as condições concretas em que ocorre o ensino e seus diferentes momentos, planejamento, realização e avaliação. Em outros termos, a tarefa de intervenção no ensino escolar é basicamente do professor e consiste em dirigir, orientar, no planejamento, na realização das aulas e das atividades extraescolares e na avaliação (CAVALCANTI, 2006, p.38).

Essa concepção afasta-se da ideia do ser professor apenas como simples transmissor de conhecimentos para os alunos. O ser professor de geografia é representado como sujeito ativo, porque faz a mediação do aluno com os objetos de conhecimento, e também, passivo, pois no ato de ensinar ele também aprende numa relação de interação com os alunos.

Essa concepção do ser professor evidenciou-se nas evocações mediador, orientador, desenvolvimento, ensinar e aprendizagem, esta última repetida duas vezes por discentes distintos, definidas pelos Alunos B VIII (3), (5), (7), (9) e (12), significando, nessa ordem: "auxiliar o desenvolvimento do aluno por meio da aprendizagem", "intervir para que o aluno possa aprender", "é ajudar no desenvolvimento do aluno para que ele possa aprender analisar a sua realidade com um olhar crítico", "buscar instrumentos para efetivar aprendizagem da analise espacial", "ajudar o aluno a aprender" e "orientar pra aprendizagem do aluno com o desenvolvimento do senso crítico".

Assim, percebe-se que, dos 12 (doze) discentes do $8^{\circ}$ período, 6 (seis) estudantes concebem a relação do conhecimento com a aprendizagem mediada pelo professor, constituindo um percentual de $50 \%$ (cinquenta por cento) deste grupo. A partir dessa evidência emerge a categoria professor mediador.

Nesse sentido, destaca-se o papel do professor como instrumento significativo no processo de aprendizagem. No tocante à relação conhecimento, aprendizagem e o caráter mediador do professor, 
Vygotsky (1984, p.97) elabora o conceito de Zona de Desenvolvimento Proximal (ZDP), sendo ela definida como:

[...] a distância entre o nível de desenvolvimento do real, que se costuma determinar através da solução independente de problemas, e o nível de desenvolvimento potencial, determinado através da solução de problemas sob a orientação de um adulto ou em colaboração com companheiros mais capazes.

Diante desse entendimento, e por meio da análise do TALP, foi possível refletir sobre a importância de se considerar o conhecimento prévio do aluno no processo de ensino e aprendizagem. Além disso, é importante discutir como ocorre esse processo de ensino e aprendizagem, que deve ser concebido antes como um processo de reconstrução, levando em consideração também as representações sociais.

Nesse contexto, corroborando com essa afirmação, Libâneo (1994, p.88) preceitua que "o trabalho docente é atividade que dá unidade ao binômio ensino-aprendizagem, pelo processo de transmissão-assimilação ativa de conhecimentos, realizando a tarefa de mediação na relação cognitiva entre o aluno e as matérias de estudo".

Em contrapartida, assim como na categoria analítica da representação sobre Licenciatura, o termo vocação também foi citado, pelos discentes do $8^{\circ}$ período, como representação do ser professor de geografia, com significado semântico próximo às palavras realização e missão, que foram evocadas pelos Alunos B VIII (2) e (11)edefinidas, nesta ordem, como "gostar de ser professor" e "ter o dom de ensinar".

Verifica-se que nessa acepção a representação social do ser professor está ligada ao sentido de sentir-se realizado, algo que se aproxima de ter o "dom” para exercer a profissão. Nesse sentido, Sousa (1996, p. 103) afirma que "o professor quando perde o espaço público do social busca explicação no âmbito individual, na vocação para permanecer na docência”.

No caso da presente investigação, a afirmação de Sousa (1996) encontra ressonância na representação do Aluno B VIII (8), que afirma: "é preciso ter vocação para ser professor e superar as dificuldades". Essa concepção eufemiza os traços de profissionalismo da profissão docente, uma vez que denota ausência de uma consciência teórica a respeito do trabalho docente, bem como sugere uma redução desse trabalho à dimensão moral. 
No entanto, deve-se ressaltar que, nessa representação, o Aluno BVIII (8), ao representar o ser professor como uma realização, não faz isso de forma totalmente acrítica, pois ele tem consciência das dificuldades e dos obstáculos que constituem o ser professor e suscita a possibilidade, mesmo que seja por condição exclusiva do próprio professor, uma superação das dificuldades e dos obstáculos em questão.

Na manifestação do Aluno BVIII (1) verifica-se que a representação do ser professor de geografia sugere um "profissional que incentiva o aluno a memorizar os conhecimentos da geografia e a analisar o espaço". Sob esse aspecto, considerando a literatura referente à prática pedagógica do professor de geografia, observa-se que, segundo a perspectiva tradicional, aprender geografia era sinônimo de memorizar o maior número possível de nomes de capitais, rios etc. Nessa perspectiva o ensino de geografia seria visto como atividade menor, posto que seria pouco criativo e consistiria apenas em repetição para memorização.

Dessa forma, pode-se compreender que a representação do Aluno B VIII (1) está ancorada não apenas nos pressupostos da perspectiva tradicional, posto que além do termo "memorizar" ele incorpora à sua fala o termo "analisar o espaço". O que se manifesta como uma tentativa de não relacionar exclusivamente a função do professor de geografia com um ensino fundamentado apenas na memorização.

Os Alunos B VIII (4) e (6) representaram o ser professor de geografia como ativista e crítico, conceituando estes termos, respectivamente, como "agente transformador da sociedade através da educação" e "ver a sociedade com um olhar crítico". Por esses escritos, vê-se que o objeto representacional "professor de geografia" é visto como estando vinculado a uma ação política transformadora e, assim, assemelha-se à representação sobre geografia dos discentes do $8^{\circ}$ período, identificada na seção 4.1 do presente estudo.

Nesse sentido, é oportuna a citação de Moscovici (1978), que afirma que as representações são construídas nas interações cotidianas. Este autor entende que as representações são sociais, mas também cognitivas, afetivas e históricas. Destaca ele ainda que a construção das representações ocorre a partir do contato dos indivíduos com o conhecimento científico e sua posterior interpretação, trazendo-os para o seu universo conceitual comum.

Assim, pode-se inferir que os termos crítico e ativista indicam formas de se ensinar Geografia, bem como o sentido que o fazer docente deve seguir. Observa-se ainda, a partir dessa evocação, a 
dimensão simbólica e a atribuição de sentido ao ser professor de geografia. Essa representação parte de um campo social em que se constroem os sentidos do ensinar geografia e da própria existência dessa ciência.

As falas desses discentes partem da sua inserção no campo acadêmico, geográfico e também da acumulação de um conjunto de capitais, quais sejam, cultural, econômico, cognitivos e sociais e que compõem a formação desses estudantes ao longo das suas trajetórias escolares e acadêmicas.

Nesse contexto, as cognições crítico e ativista estão ligadas às condições históricas e ideológicas constituídas no interior do desenvolvimento epistemológico da Geografia. Esses termos estão marcados, pela influência do campo acadêmico, nos pressupostos da Geografia Crítica, a partir dos quais se impõe a necessidade da superação da Geografia Tradicional, atribuindo por vezes um necessário caráter radical e ideológico aos fazeres a partir dos estudos geográficos.

Acredita-se que a identificação e compreensão do significado do ser professor de geografia, a partir do olhar dos licenciandos, permite-nos inferir como eles constroem o conhecimento na academia e quais são as condições nas quais se desenvolve sua formação e sua profissão, uma vez que os sujeitos constroem representações pra lhes servirem de guia nos espaços em que transitam.

É preciso refletir sobre as análises e os posicionamentos apresentados nas falas dos discentes, para que assim se possa compreender a diversidade de formas assumidas pelas representações dos licenciandos sobre o ser professor de geografia e, a partir disso, refletir e suscitar também mudanças sobre a prática docente, o que, por consequência, alimenta as próprias representações. O perfil atribuído ao professor de geografia são algumas expressões dessas formas.

\section{CONSIDERAÇÕES FINAIS}

Por todos os aspectos mencionados, pode-se afirmar que a representação social do ser professor de geografia, para os discentes do segundo período, caracteriza a profissão docente de forma diversificada, de tal modo que cada manifestação por eles revelada confere um sentido ao ser professor de Geografia, permitindo identificar a essência desse fenômeno como fato materialmente percebido. E, assim, o ser professor, para eles, centra-se na concepção do ensinar e de sua função, tendendo a não ser um fenômeno com caráter cognitivo vinculado à dimensão afetiva de transmissão 
de valores e princípios e fomentando no processo de ensino e aprendizagem a construção da subjetividade do aluno.

Para os discentes do oitavo período, a representação do ser professor de geografia aparece ancoradas nos pressupostos científicos da didática critico-social, sendo ele representado como sujeito ativo, pois faz a mediação do aluno com o conhecimento científico.

Identificou-se ainda, que as representações sobre o ser professor de geografia ocorrem em uma esquematização entre aspectos objetivos, vinculados à baixa remuneração salarial e aspectos subjetivos, relacionados ao sentido do processo de ensino e aprendizagem. Dessa convergência entre o social e o subjetivo os discentes formam a sua consciência, orientando o modo próprio de pensar a profissão docente. Esses fatores influenciam também a construção da identidade do ser professor de geografia.

Nesse contexto, pode-se inferir que na formação inicial do professor de geografia está uma das possibilidades de mudança das representações sociais, o que pode ser tomado como referência para reforçar pontos específicos que podem auxiliar no processo de alteração do núcleo representacional e, por conseguinte, na promoção da identidade docente adequada às demandas educacionais da atualidade.

Finalmente, por meio desta pesquisa, foi possível alcançar o objetivo de efetuar uma análise da condição do ser professor de geografia, desenvolvendo-a à luz da teoria das representações sociais. Entende-se, desse modo, que esta pesquisa não esgotou todas suas possibilidades, mas pretendeu fornecer novos subsídios para novos olhares e novas discussões, ampliando o leque de enfoques acerca do tema em pauta.

\section{REFERÊNCIAS}

ARROYO, Miguel G. Oficio de Mestre: imagens e auto-imagens. 11. ed. Petrópolis, RJ: Vozes, 2001.

BARDIN, L. Análise de conteúdo. Lisboa: Edição 70, 1986.

BICUDO, M. A. V. Pesquisa qualitativa olhada para além dos seus procedimentos. In: BORBA, M; ARAUJO, J. L. (Orgs.). Pesquisa qualitativa segundo a abordagem fenomenológica. São Paulo: Cortez, 2011. p. 11-29.

BORDIEU, P. Escritos de Educação. 4.ed. Petrópolis-RJ: Vozes, 2002. 
BRASIL. Lei de Diretrizes e Bases da Educação Nacional: Lei n. 9394/96. 3. ed. Brasília: Câmara dos Deputados, Coordenação de Publicações, 2005.

CALLAI, Helena Copetti. A formação do profissional da geografia: (O professor). 2. Ed. Ijuí: Unijuí, 2013.

CAVALCANTI, L. de S. Geografia, escola e construção de conhecimento. Campinas - SP: Papirus, 1998.

DELORS, J. Educação: um tesouro a descobrir. São Paulo, Cortez, 1998.

FREIRE, Paulo. Pedagogia da Autonomia. 43. ed. Rio de Janeiro. Paz e Terra, 2011.

GADOTTI, Moacir. Perspectivas atuais da educação. Porto Alegre, Ed. Artes Médicas, 2000.

GRAVES, Robert. Os Mitos Gregos I. Tradução de Fernanda Branco. Lisboa: Publicações Dom Quixote, 1990.

JODELET, D. Representações Sociais: um domínio em expansão. In. JODELET, D. (Org.) As representações sociais. Rio de Janeiro. EdUERJ. 2001.

KAERCHER, N. A. Desafios e utopias no ensino de Geografia. 3.ed. Santa Cruz do Sul-RS, EDUNISC, 2007.

MINAYO, M. C. O desafio do conhecimento: pesquisa qualitativa em saúde. Rio de Janeiro: HUCITEC, 1994.

MONBEIG, P. Papel e Valor do Ensino da Geografia e de sua Pesquisa. IBGE - Conselho Nacional de Geografia, Rio de Janeiro. 1956.

MOSCOVICI, Sergi. A Representação Social da Psicanálise. Rio de Janeiro: Zahar Editores, 1978.

MORIN, Edgar. A cabeça bem- feita: repensar a reforma, reformar o pensamento. 11 ed. Rio de Janeiro: Bertrand Brasil, 2005.

NASCIMENTO, Samuel Pontes do. O poder econômico na educação superior: uma análise da mercantilização do ensino superior no Brasil sob a ótica do Direito Econômico. Teresina. Editora da Universidade Federal do Piauí - Edufpi, 2018.

NÓVOA, Antônio. Concepções e práticas da formação contínua de professores: In: Nóvoa A. (org.). Formação contínua de professores: realidade e perspectivas. Portugal: Universidade de Aveiro, 1991. 
PONTUSCHKA, Nídia Nacib; PAGANELLI, Tomoko, Iyda; CACETE, Núria Hanglei. Para ensinar e aprender Geografia. São Paulo: Cortez, 2009.

RIBEIRO, Maria Luisa Santos. História da educação brasileira: a organização escolar. 15. ed. Campinas: Autores Associados, 1998.

SANTOS. C.S; ANDRADE, F. C. Representações Sociais e formação do professor: revelando interseções do discurso. 1. ed. João Pessoa: Editora Universitária/ UFPB. 2002.

SEABRA, M.F.G. Estudos Sociais e vulgarização do magistério e do ensino de $1^{\circ}$ e $2^{\circ}$ graus. Boletim Paulista de Geografia, Associação dos Geógrafos Brasileiros- Seção São Paulo, n ${ }^{\circ}$, 1981.

SILVA, Josélia Saraiva. Habitus docente e representação social do "ensinar geografia" na educação básica de Teresina- Piauí. Tese. (Doutorado em Educação). Faculdade de Educação. Universidade Federal do Rio Grande no Norte. 2007.

TARDIF, Maurice. Saberes docentes e formação profissional. 11. ed. Petrópolis, RJ: Vozes, 2002.

VYGOTSKY, L. S. A formação social da mente. São Paulo: Martins Fontes, 1984, p.97.

\footnotetext{
${ }^{\text {i }}$ A expressão B II corresponde a um aluno do segundo período do curso de Licenciatura em Geografia de uma Instituição de Ensino Superior pública localizada em Teresina-PI.

${ }^{\text {ii }}$ A expressão B VIII corresponde a um aluno do oitavo período do curso de Licenciatura em Geografia de uma Instituição de Ensino Superior pública localizada em Teresina-PI.
} 